4. Civetta, J. M.: The inverse relationship between cost and survival. J. Surg. Res., 14: 265 (1973).

5. Cohn, J. N Franciosa, J. A., Francis, G. S., Archibald, D., Tristani, F. Montero, A Cintron, G., Clarke, J., Hager, D., Saunders, R., Cobb, F. Smith, R., Loeb, H., Settle, H.: Effect of short-term infusion of sodium nitroprusside on mortality rate in acute myocardial infarction complicated by left ventricular failure. Results of a veterans cooperative study. N. Engl. J. Med., 306: 1129 (1982).

6. Cowley, R. A.; Sacco, W. J., Gill, W., Champion, H. R., Long, W. B., Goldfarb, M. A., and Sperrazza, J.: A prognostic index for severe trauma. J. Trauma, 14: $1029(1974)$

7. Cullen, D. J., Civetta, J. M., Briggs, B. A., and Ferrara, L. C.: Therapeutic intervention scoring system: a method for quantitative comparison of patient care. Crit. Care Med., 2: 57 (1974)

8. Cullen, D. J., Ferrara, L. C., Briggs, B. A., Walker, P. F., and Gilbert, J.: Survival hospitalization charges and follow-up results in critically ill patients. N. Engl. J. Med., 294: 982 (1976).

9. Dixon, W. J. and Brown, M. B.: BMPD-79, Biomedical Computer Programs. pp. 517.1-517.13. (University of California Press, Berkeley, 1979)

10. Durrer, J. D., Lie, K. I., Capelle, L. V., and Durrer, D.: Effect of sodium nitroprusside on mortality in acute myocardial infarction. N. Engl. J. Med., 306: 1121 (1982).

11. Hughes, W. L., Kalbfleisch, J. M., Brandt, E. N., and Costible, J. P.: Myocardial infarction: prognosis by discrimination analysis. Arch. Intern. Med., 111: 338 (1963).

12. Knaus, W. A., Zimmerman, J. E., Wagner, D. P., Draper, E. A. and Lawrence, D. E.: APACHE-acute physiology and chronic heaith evaluation: a physiologically based classification system. Crit. Care Med., 9: 591 (1981).

13. Norris, R. M., Brandt, P. W., Caughey, D. E., Lee, A. J., and Scott, P. J.: A new coronary prognostic index. Lancet, $1: 274$ (1969).

14. Pierchala, C. Shoemaker, W. C., Chang, P.: A comparison of some methods for early classification of survivors and nonsurvivors of postoperative shock. Comp. Biol. Med., 8: 279 (1978).

15. Rothstein, P. and Johnson, P.: Pediatric intensive care: factors that influence outcome. Crit. Care Med., 10: 34 (1982).

16. Shoemaker, W. C., Chang, P., Czer, L., et al.: Cardiorespiratory monitoring in postoperative patients. I. Predictor of outcome and severity of illness. Crit. Care Med., 7: 237 (1979).

17. Shoemaker, W. C., Pierchala, C., Chang, P., Bland, R., Czer, L., Shabot, M., and Clifton, J. F.: Prediction of outcome and severity of illness by analysis of the frequency distributions of cardiorespiratory variables. Crit. Care Med., 5: $82(1977)$.

18. Silverman, D. G., Goldiner, P. L., Kaye, B. A., Howland, W. S., Turnbill, A. D.: The therapeutic intervention scoring system. An application to acutely ill cancer patients. Crit. Care Med., 3: 222 (1975).

19. Yeh, T. S., Pollack, M. M., Holbrook, P. R., Fields, A. I., and Ruttiman, U.: Assessment of pediatric intensive care-application of the therapeutic intervention scoring system. Crit. Care Med., 10: 497 (1982).

20. Presented at the American Pediatric Society and the Society for Pediatric Research Meetings, May, 1982.

21. The authors wish to acknowledge the assistance of Martha Wallace in the data collection and the encouragement of Drs. William Knaus and Douglas Wagner.

22. Requests for reprints should be addressed to: Murray M. Pollack, M.D. is: Associate Director, ICU, Children's Hospital National Medical Center, 111 Michigan Avenue, N.W., Washington, D.C. 20010

23. Received for publication November $22,1982$.

24. Accepted for publication July 19, 1983.

\title{
Ontogeny of the Immune System: Fetal Lamb as a Model
}

\author{
RUKMANI RAGHUNATHAN, ${ }^{(31)}$ MICHAEL E. MILLER, CARLA WUEST, AND JUDY FAUST \\ Department of Pediatrics, UCLA School of Medicine, Harbor-UCLA Medical Center, Torrance, California and \\ University of California, Davis School of Medicine, Sacramento, California, USA [M.E.M., C.W.]
}

\section{Summary}

We examined adult sheep lymphocytes for the following surface markers: Surface membrane immunoglobulin, antigen identified by anti-sheep thymocyte globulin and complement receptors. We quantitated sheep peripheral blood mononuclear leukocyte proliferative responses to mitogens and alloantigens, and demonstrated a neutrophil-directed chemotactic factor $(\mathbf{N}$ LDCF) liberated by mitogen-stimulated sheep mononuclear cells. A comparison of adult and fetal sheep from 120-150 d of gestation demonstrated that 1) fetal sheep had adult proportions of surface membrane Ig+ and $\mathrm{T}+$ lymphocytes but a significant decrease in FcIgG receptor+ lymphocytes, 2) proliferative responses of fetal sheep blood mononuclear cells to mitogens and alloantigens were comparable to adult responses, and 3) fetal mononuclear leukocytes failed to produce the lymphokine, $\mathrm{N}$ LDCF, in response to mitogen stimulation.

\section{Abbreviations}

BSA, bovine serum albumin

CCE, counterflow centrifugation elutriation

CPM, counts/min

EA, antibody-coated sheep red cells
EAC, antibody- and complement-coated sheep red cells

FclgG, Fc portion of IgG

FITC, fluorescein isothiocyanate

FITC $F(a b)_{2}$ RxSIg, FITC conjugated $F(a b)_{2}$ fraction of rabbit anti-sheep Ig

GxRIg, goat anti-rabbit immunoglobulin

HBSS, Hanks balanced salt solution

LCM, lymphocyte culture medium

MFCS, McCoy's 5a medium with fetal calf serum

MHC, major histocompatibility locus

MLC, mixed leukocyte cultues

MNL, mononuclear leukocyte

N-LDCF, neutrophil-directed chemotactic factor

PMN, polymorphonuclear leukocytes

RAST, rabbit anti-sheep T-cell antibody

RITC, rhodamine isothiocyanate

RxSIg, rabbit anti-sheep immunoglobulin

SmIg, surface membrane immunoglobulin

Knowledge of the immune system's ontogeny is essential in understanding both the response of the fetus to intrauterine infections and other antigenic insults, and the effects of these 
insults on the developing immune system. The fetal lamb provides an excellent model for the study of the ontogeny of the immune system because of 1) large size of the fetus and accessibility that facilitates sequential sampling in utero, 2) long gestational period $(150 \mathrm{~d})$ that enables adequate dissection of events, and 3) unique placentation that maintains the fetus agammaglobulinemic during gestation.

The cellular immune system in sheep has been assessed by measuring in vitro MNL proliferative responses to soluble antigens $(13,21)$ and allo- and xenoantigens (2). The available data on the ontogeny of mitogen responses in sheep are not conclusive because splenic and blood MNL, which would be expected to demonstrate this function in the latter half of gestation, were not studied (17). The absence of an easily identifiable T cell marker in sheep has hampered the analysis of results from intrauterine immune manipulations, such as thymectomy in this animal model $(9,10)$. Previous studies in ovine and other species suggest development of the afferent arm of the immune response represented by proliferative responses before development of the efferent arm represented by effector cells $(14,29)$. The ontogeny of lymphokine production has not been evaluated in this animal model.

\section{MATERIALS AND METHODS}

In this study, adult sheep were first examined for selected surface markers. Smlg was chosen as a B cell marker. An antithymocyte globulin developed in rabbits against fetal lamb thymocytes was used to identify sheep $T$ cells. FcIgG and complement receptors on lymphocytes were examined as additional markers. MNL proliferative responses to mitogenic lectins and alloantigens were determined. A N-LDCF produced by phytohemagglutinin-stimulated sheep MNL was demonstrated, and this lymphokine (N-LDCF) was used as an additional parameter for MNL function. Comparative studies of blood lymphocytes and MNL from fetal and adult sheep demonstrated that 1) fetal lamb at and after $120 \mathrm{~d}$ of gestation had adult proportions of $\mathrm{T}$ and B cells in the peripheral blood, 2) fetal lamb had decreased numbers of FcIgG receptor-bearing lymphocytes, 3) fetal MNL proliferative responses to phytomitogens and alloantigens were comparable to those of adult, and 4) fetal MNL were deficient in the production of N-LDCF.

Animals and sample collection. Normal adult sheep were used as controls and heparinized blood $(10 \mathrm{U} / \mathrm{ml})$ was collected from the external jugular veins. Fetal lambs of gestational age 120 $150 \mathrm{~d}$ were compared with adults. The gestational age was determined by time-dated breeding and confirmed by fetal length. The fetuses were exposed by hysterotomy with the mother under spinal anaesthesia, and heparinized blood was obtained as soon as the fetus was exposed from cord vessels. The fetal lambs were all normal and were being delivered prematurely for other studies. The blood was processed within $30 \mathrm{~min}$.

Cell separation. Cell separation was carried out by either $\mathrm{CCE}$ or gradient centrifugation techniques. Isolation of sheep leukocytes by CCE was described previously (19); lymphocytes thus isolated were $>97 \%$ pure as judged by non-specific esterase staining: MNL contained 70-85\% lymphocytes, 10-30\% monocytes and $<5 \%$ granulocytes; PMN were $>95 \%$ pure as judged by Wright's stain.

For cell separation by gradient centrifugation, whole blood was diluted with 2-3 volumes of normal saline and layered on a Ficoll-Hypaque gradient of density $1.088 \mathrm{~g} / \mathrm{ml}$ and centrifuged at $600 \mathrm{~g}$ for $30 \mathrm{~min}$. The buffy coat at the interphase was diluted with normal saline and relayered on another gradient of density $1.088 \mathrm{~g} / \mathrm{ml}$ and centrifuged at $600 \mathrm{~g}$ for $30 \mathrm{~min}$. The MNL ring at the interphase contained $75 \%$ lymphocytes, $20 \%$ monocytes, and $5 \%$ granulocytes, as judged by non-specific estease staining. Preliminary experiments demonstrated that with sheep blood, this two-step gradient centrifugation procedure provided optimal yield $(>80 \%)$ of suitable MNL populations.
The lymphocyte or MNL suspension was washed and standardized at $2 \times 10^{6}$ lymphocyte $/ \mathrm{ml}$ in either RPMI-1640 with $10 \%$ fetal calf serum, $2 \mathrm{mM}$ L-glutamine, and antibiotic antimyotic solution (LCM) for cell cultures, or HBSS for surface marker studies.

Preparation of RAST. Young New Zealand white rabbits were immunized with 4-6 bi-weekly IV injections of $1-5 \times 10^{8}$ freshly isolated fetal lamb thymocytes. The rabbits were bled by cardiac puncture. The antiserum, after complement inactivation, was adsorbed twice with $1 / 10$ vol of packed sheep red cells, powdered lamb liver ( $1 \mathrm{~g} / 10 \mathrm{ml}$ of serum), and sheep immunoglobulincoated glass beads. Ammonium sulphate precipitate $(0.35 \%)$ from the antiserum was washed, dialyzed, and redissolved to half the original volume in phosphate buffered saline with $2.5 \%$ bovine serum albumin.

Determination of specificity of RAST. Preliminary experiments demonstrated that RAST at a dilution of 1:50 was cytotoxic, in the presence of complement, to $60-80 \%$ of peripheral blood lymphocytes and $>95 \%$ of sheep thymocytes. By indirect immunofluorescence technique as described below, using FITCGxRIg as the second antibody, RAST identified a similar number of peripheral blood lymphocytes and thymocytes. RAST did not stain granulocytes or monocytes. An aliquot of RAST was conjugated with RITC. Double immunofluorescence studies using RITC-RAST and FITC-RxSIG demonstrated that the RITCRAST reacted only with SmIg negative lymphocytes or non-B cells.

Immunofluorescence. To demonstrate SmIg+ lymphocytes, a direct immunofluorescence technique with FITC $\mathrm{F}(\mathrm{ab})_{2} \mathrm{RxSIg}$ (Calbiochem-Behring, LaJolla, CA) was used. This antibody was reconstituted according to manufacturer's instructions and diluted to $50 \%$ with HBSS-BSA and frozen at $-70^{\circ} \mathrm{C}$ in small aliquots. Just before use, the required amount was thawed, diluted to a final concentration of $5 \%$ with HBSS-BSA, and centrifuged in a Beckman microfuge for $10 \mathrm{~min}$ at $25,000 \mathrm{~g}$ to remove aggregates. Lymphocytes $\left(2 \times 10^{5}\right)$ pelleted in a $2 \times 10$ $\mathrm{cm}$ tube were incubated with $0.1 \mathrm{ml}$ of $5 \%$ FITC-RxSIg at $4^{\circ} \mathrm{C}$ for $30 \mathrm{~min}$ and then washed with an excess of cold HBSS-BSA. The cells were then fixed with $0.1 \%$ paraformaldehyde for $5 \mathrm{~min}$ at room temperature. After further washes, wet mounts were prepared and sealed.

To demonstrate sheep T cells, an indirect immunofluorescence technique was used with RAST as the first antibody and FITCGxRIg as the second antibody. RAST in HBSS-BSA (1:100) was centrifuged at $25,000 \mathrm{~g}$ for $10 \mathrm{~min}$ in a Beckman microfuge to remove aggregates, and then incubated with $2 \times 10^{5}$ lymphocytes at $4^{\circ}$ for $30 \mathrm{~min}$. After three washes with excess cold HBSS-BSA, the cells were incubated for $30 \mathrm{~min}$ at $4^{\circ} \mathrm{C}$ with $5 \%$ FITC-GxRIg which was reconstituted and stored, as described for FITC $\mathrm{F}(\mathrm{ab}){ }_{2} \mathrm{RxSIg}$. The cells were washed with excess cold HBSS-BSA, fixed with $0.1 \%$ paraformaldehyde and mounted. Controls for sheep $\mathrm{T}$ cell demonstration included globulin fraction prepared from normal rabbit serum which was inactivated and absorbed similar to RAST as the first antibody followed by FITC-GxRIg and FITC-GxRIg alone.

The slides were kept at $4^{\circ} \mathrm{C}$ in the dark until read within $72 \mathrm{~h}$ with a Nikon fluorescence microscope. Lymphocytes exhibiting a uniform peripheral ring fluorescence were counted as positive. Capping was not seen under these conditions. Lymphocyte preparations isolated by CCE and MNL preparations isolated by gradient centrifugation gave identical values. Monocytes were easily identifiable and exhibited minimal fluorescence. Binding of aggregates to $\mathrm{Fc}$ receptor was felt to be minimal under the test conditions.

Demonstration of FcIgG receptor-and $C^{\prime}$ receptor-bearing lymphoyctes. A rosetting technique, utilizing IgG EA or IgM EAC, was used to demonstrate FCIgG and complement receptors, respectively. Sheep red cells, after removal of buffy coat leukocytes, were washed and resuspended at a concentration of $10 \%$ in HBSS and treated with 1:2500 dilution of $7 \mathrm{~S}$ (IgG) rabbit anti- 
sheep red cell antibody for EA preparation or 1:750 dilution of 19S (IgM) rabbit anti-sheep red cell antibody for EAC preparation (Cordis Laboratory, Miami, FL). After incubation at $37^{\circ} \mathrm{C}$ for $20 \mathrm{~min}$, the sensitized red cells were washed three times in excess cold HBSS-BSA. The IgM EA were resuspended as a $5 \%$ suspension, incubated for $10 \mathrm{~min}$ at $37^{\circ} \mathrm{C}$ with $10 \%$ fresh-frozen pooled adult sheep plasma as a source of complement, and then washed three times with cold HBSS-BSA. The EA and EAC reagents were resuspended as $1 \%$ suspensions.

Preparation of $E A$ and $E A C$ rosettes. Equal volumes of lymphocytes or MNL suspension and EA or EAC reagent were mixed in duplicate tubes, centrifuged at $200 \mathrm{~g}$ for $5 \mathrm{~min}$, and incubated at room temperature for $10 \mathrm{~min}$. The rosettes were fixed with $0.1 \mathrm{ml}$ of $0.5 \%$ glutaraldehyde for $5 \mathrm{~min}$ at room temperature. After vortexing to minimize non-specific clumping, cytocentrifuge preparations were made with a Shandon cytocentrifuge and the slides were stained for non-specific esterase staining activity. Two hundred lymphocytes were counted in duplicate slides and the number of lymphocytes with $\geq 3$ rosetted red cells was reported as a percentage.

In vitro lymphocyte blastogenesis. Cultures were performed with MNL separated by gradient centrifugation or CCE. Lymphocytes $\left(2 \times 10^{5}\right)$ in $0.1 \mathrm{ml}$ of LCM were cultured in triplicate in u-bottomed microtiter plates, with or without mitogens. The mitogens tested were phytohemagglutinin (Burroughs-Wellcome, Granville, NC), pokeweed mitogen (Gibco, Grand Island, NY), and Concanavalin A (Sigma Chemical, St. Louis, MO) in doses ranging from $0.25 \mu \mathrm{g} /$ well-0.025 $\mu \mathrm{g} /$ well. Autologous or allogeneic stimulator MNL for MLC were first treated with mitomycin$\mathrm{C}\left(10 \mu \mathrm{g} / \mathrm{ml} / 2 \times 10^{6}\right.$ lymphocytes $)$ for $30 \mathrm{~min}$ at $37^{\circ} \mathrm{C}$ and washed three times. Equal numbers of responder and stimulator cells were cultured in LCM. The cultures were incubated at $37^{\circ} \mathrm{C}$ in humidified air with $5 \% \mathrm{CO}_{2}$ for $3 \mathrm{~d}$ (mitogens) or $6 \mathrm{~d}$ (MLC). During the last $18 \mathrm{~h}$ of culture, $0.08 \mu \mathrm{Ci} /$ well of $\left[{ }^{3} \mathrm{H}\right]$ thymidine (TRK-120-Amersham, Arlington Heights, IL) was added. The cells were harvested onto fiberglass filters using an automatic cell harvester. The dried filter discs were counted in a scintillation counter for $\left[{ }^{3} \mathrm{H}\right]$ thymidine uptake. Results were expressed as mean $\mathrm{CPM} \pm \mathrm{SE}$.

$L D C F$ generation. Normal adult and fetal MNL at a concentration of $2 \times 10^{6}$ lymphocyte $/ \mathrm{ml}$ in LCM were simultaneously cultured with or without $1.0 \mu \mathrm{g} / \mathrm{ml}$ of phytohemagglutinin for $48 \mathrm{~h}$ in $5 \% \mathrm{CO}_{2}$-enriched humidified air. The unstimulated and stimulated culture supernates were frozen in aliquots at $-70^{\circ} \mathrm{C}$ until assayed for chemotactic activity. Phytohemagglutinin was added to unstimulated culture supernates at the end of the culture. Preliminary experiments established these optimal conditions for lectin-induced chemotactic factor generation.

Chemotaxis. Normal adult sheep PMN isolated by CCE were used as the indicator cells for demonstration of N-LDCF activity. These cell suspensions contained $>97 \%$ PMN. Briefly, $1 \times 10^{5}$ PMN in $0.2 \mathrm{ml}$ of MFCS (Gibco) were separated from various dilutions of stimulated or unstimulated lymphocyte culture supernates in MFCS by a 3- $\mu \mathrm{m}$ diameter pore size polycarbonate chemotactic filter (Nuclepore Corp., Pleasanton, CA) in acrylic blind well chambers (Biorad, Richmond, CA). Normal adult MNL, unstimulated, and phytohemagglutinin-stimulated supernates were assayed for N-LDCF activity along with the fetal samples. PMN chemotaxis towards MFCS alone and $20 \%$ endotoxin-activated fresh-frozed pooled adult sheep plasma as a source of complement-derived chemotactic factor (18) were tested simultaneously to confirm the normal function of these indicator PMN. After incubation at $37^{\circ} \mathrm{C}$ in a humidified atmosphere for $45 \mathrm{~min}$, the filters were stained with hematoxylin and Wright's stains. The number of PMN that migrated across the filter were counted under an oil immersion lens (magnification, $\times 1000)$ in 10 fields in triplicate filters, and results were reported as cell/field. LDCF was defined to be present in the culture supernates if net chemotaxis $=$ cell/field with stimulated culture supernate - cell/field unstimulated culture supernate was $\geq 10$.
At least three dilutions of lymphocyte culture supernates were tested.

\section{RESULTS}

Surface markers of adult and fetal sheep lymphocytes. Results are presented in Table 1 . T cells, identified by RAST, constituted $76.8 \pm 11.4 \%$ (mean \pm SD) of peripheral lymphocytes of adult, and $82.7 \pm 9.9 \%$ of fetal lymphocytes. SmIg+ lymphocytes constituted $15.0 \pm 9.2 \%$ of adult and $10.8 \pm 5.5 \%$ of fetal lymphocytes. The difference in the mean number of $B$ cells between the adult and the fetus was not statistically significant. FcIgG receptor-bearing lymphocytes constituted $21.43 \pm 5.97 \%$ of adult and $9.58+3.1 \%$ of fetal lymphocytes. The difference between the adult and fetal values was significant $(P<0.001)$ by Student's $t$ test. $C^{\prime}$ receptor-bearing lymphocytes constituted $17.18 \pm 6.6 \%$ of adult and $14.0 \pm 5.9 \%$ of fetal lymphocytes. The difference in these numbers was not statistically significant.

In vitro lymphocyte blastogenesis. Fetal MNL, in the unstimulated state, showed high rate of proliferation as evidenced by increased thymidine uptake compared with the adult, but this was not statistically significant. Table 2 summarizes the results of adult and fetal MNL responses to single doses of the three mitogens. Though the stimulated CPM values tended to be similar between adult and fetal MNL, the stimulation indices calculated as stimulated CPM $\div$ unstimulated CPM were somewhat lower with fetal MNL because of higher unstimulated CPM. The differences between adult and fetal MNL responses were not statistically significant. Similar proliferative responses were seen over the range of doses of mitogens tested.

Results of MLC are summarized in Table 3. Adult MNL proliferated in response to adult and fetal allogeneic cells. Similarly, fetal MNL responded to allogeneic adult and fetal cells. Three fetal sheep were tested against MNL from their twins, mother, and unrelated adult. All three failed to respond to cells from the twins while responding normally to unrelated adult MNL. The response to maternal cells was roughly half of response to unrelated cells (Table 4).

$N-L D C F$ generation by adult and fetal MNL. Phytohemagglutinin-induced N-LDCF generation from adult MNL is shown in Figure 1. The mean number of cell/field with unstimulated adult MNL culture supernates was $1.5 \pm 0.5$ (mean \pm SD of triplicate filters). Phytohemagglutinin-stimulated adult MNL culture supernates exhibited chemotactic activity that was demonstrable at $10 \%$ dilution. The nine adult MNL tested produced N-LDCF in response to phytohemagglutinin as represented by a net chemotaxis $=16.3 \pm 2.0$ (mean $\pm \mathrm{SE}$ ) shown in Figure 2. Fetal lamb MNL, similar to adult MNL, did not produce any chemotactic activity in the unstimulated state (cell/field $=1.5 \pm 0.4)$. The fetal MNL differed from adult MNL in their response to phytohemagglutinin. They produced significantly lower amounts of chemotactic activity in response to phytohemagglutinin. Comparison of phytohemagglutinin-induced N-LDCF generation by adult and fetal sheep MNL is shown in Figure 2, where the net chemotaxis is represented with the culture supernates tested at a dilution of $10 \%$. The difference in the net chemotaxis between the adult and fetal MNL was due entirely to differences in the LDCF activity of stimulated culture supernates because the

Table 1. Surface markers of sheep lymphocytes

\begin{tabular}{lcccc}
\hline & *RAST + & *SmIg+ & C'receptor+ $^{\prime}$ receptor+ \\
\hline $\begin{array}{cccc}\text { Adult } \\
(n=9)\end{array}$ & $76.8 \pm 11.4 \dagger$ & $15.0 \pm 9.2$ & $14.4 \pm 9.5$ & $21.4 \pm 5.9 \ddagger$ \\
$\begin{array}{c}\text { Fetus } \\
(n=10)\end{array}$ & $82.7 \pm 9.9$ & $10.8 \pm 5.8$ & $14.0 \pm 5.9$ & $9.5 \pm 3.1 \ddagger$ \\
\end{tabular}

* RAST, SmIg, and FclgG: see "abbreviations."

$\dagger$ Percentage lymphocytes, mean \pm SD.

$\ddagger P<0.001$ by Student's $t$ test. 
RAGHUNATHAN $E T A L$.

Table 2. Mitogen responses of adult and fetal sheep*

\begin{tabular}{lccccccc}
\hline Responder & Unstimulated & PHA $\dagger$ & S.I. & ConA $\ddagger$ & S.I. & PWM $^{\S}$ & S.I.' \\
\hline $\begin{array}{l}\text { Adult } \\
(n=6)\end{array}$ & $0.96 \pm 0.30^{\S}$ & $13.9 \pm 2.35$ & $21.8 \pm 5.5$ & $33.33 \pm 5.77$ & $45.9 \pm 10.4$ & $17.42 \pm 3.24$ & $29.8 \pm 2.8$ \\
$\begin{array}{l}\text { Fetus } \\
(n=9)\end{array}$ & $4.02 \pm 199$ & $16.02 \pm 5.77$ & $10.0 \pm 4.0$ & $48.86 \pm 12.30$ & $26.1 \pm 9.5$ & $30.56 \pm 8.38$ & $28.0 \pm 13.0$ \\
\hline
\end{tabular}

* Abbreviations: PHA, phytohemagglutinin; Con A, concanavalin A; and PWM, pokeweed mitogen.

$\dagger$ PHA $0.25 \mu \mathrm{g} /$ well.

$\ddagger$ Con $\mathrm{A} 0.05 \mu \mathrm{g} /$ well.

${ }^{\S}$ PWM $0.1 \mu \mathrm{g} /$ well.

Mean SD of stimulation indices (S.I.) calculated as counts/min (CPM) stimulated $\div$ CPM unstimulated cultures.

"Mean $\mathrm{CPM} \pm \mathrm{SE} \times 10^{-3}$.

Table 3. Mixed leukocyte culture responses of adult and fetal sheep

\begin{tabular}{|c|c|c|c|}
\hline \multirow{2}{*}{$\begin{array}{c}\text { Re- } \\
\text { sponder }\end{array}$} & \multicolumn{2}{|c|}{ Stimulator* } & \multirow[b]{2}{*}{ S.I. $\dagger$} \\
\hline & Autologous & Allogeneic & \\
\hline $\begin{array}{l}\text { Adult } \\
\qquad(n=14)\end{array}$ & $3.08 \pm 0.75 \ddagger$ & $20.63 \pm 2.60$ & $9.8 \pm 1.8$ \\
\hline $\begin{array}{l}\text { Fetus } \\
\qquad(n=9)\end{array}$ & $5.31 \pm 2.46$ & $15.48 \pm 4.46$ & $7.5 \pm 2.6$ \\
\hline
\end{tabular}

* Stimulator mononuclear leukocytes were treated with mitomycin-C.

$\dagger$ Mean $\pm \mathrm{SD}$ of stimulation indices (S.I.) calculated as counts $/ \mathrm{min}$ CPM with allogeneic cells $\div$ CPM with autologous cells.

$\ddagger$ Mean \pm SE $\mathrm{CPM} \times 10^{-3}$.

Table 4. Mixed leukocyte culture responses of fetal lambs

\begin{tabular}{ccccr}
\hline & & \multicolumn{2}{c}{ Stimulator* } & \\
\cline { 3 - 4 } Responder & Autologous & Twin & Maternal & Unrelated \\
\hline 1 & $1.3 \pm 0.3 \ddagger$ & $2.5 \pm 0.6$ & $5.6 \pm 1.7$ & $12.7 \pm 1.0$ \\
2 & $1.3 \pm 0.4$ & $1.4 \pm 0.6$ & $2.9 \pm 1.2$ & $6.2 \pm 1.0$ \\
3 & $0.4 \pm 0.1$ & $0.5 \pm 0.1$ & $2.8 \pm 0.9$ & $4.6 \pm 0.5$ \\
\hline
\end{tabular}

* Stimulator mononuclear leukocytes were treated with mitomycin-C. $\ddagger$ Mean counts $/ \mathrm{min} \pm \mathrm{SD} \times 10^{-3}$.

\section{PHA INDUCED LDCF GENERATION BY OVINE MNL}

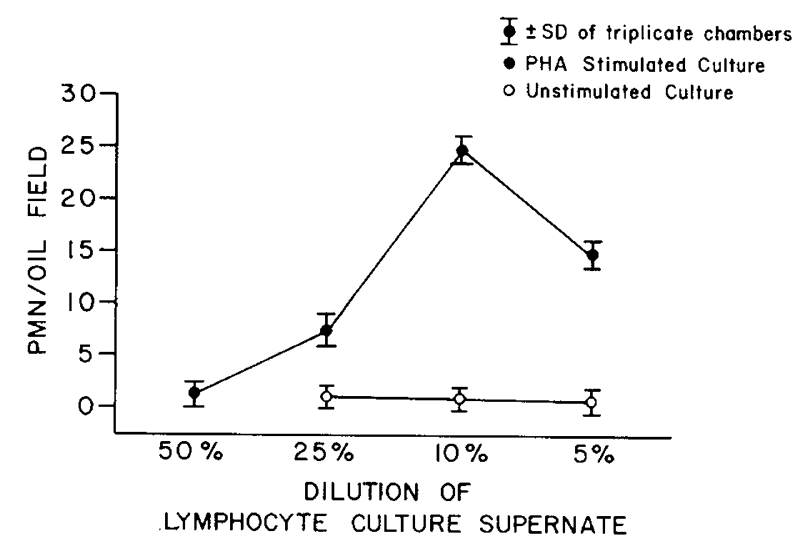

Fig. 1. Phytohemagglutinin (PHA)-induced LDCF generation by adult ovine mononuclear leukocytes (MNL). No. of polymorphonuclear leukocytes $(\mathrm{PMN}) /$ oil field with stimulated $(\longrightarrow)$ or unstimulated $(\mathrm{O}-\mathrm{O})$ culture supernates in various dilutions chemoattractants.

chemotactic activity of unstimulated culture supernates was the same in both. This difference between adult and fetal sheep MNL was statistically significant by Student's $t$ test $(P<0.001)$.

\section{DISCUSSION}

The total gestational period in the sheep is $150 \mathrm{~d}$ and the fetal lambs tested were from 120-150 d of gestation. According to the

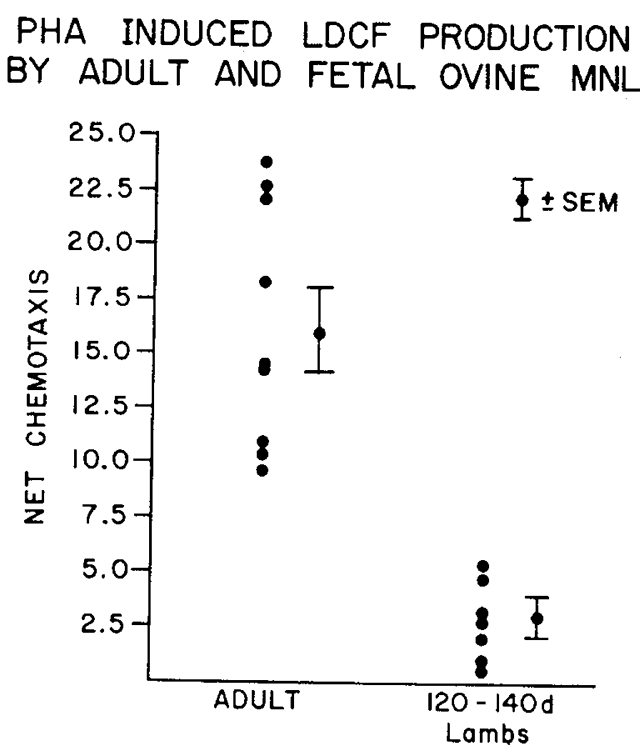

Fig. 2. Net chemotaxis = polymorphonuclear leukocytes (PMN)/ field with $10 \%$ stimulated culture supernate - PMN/field with $10 \%$ unstimulated culture supernate. PHA, phytohemagglutinin.

age equivalence curve developed by Solomon, this period corresponds to the gestational period between $32-40 \mathrm{wk}$ in humans (23).

In the fetal lambs, between 120-150 d of gestation, lymphocytes that can be identified as $T$ and $B$ cells appeared at adult levels in peripheral circulation. These data confirm previous observations $(8,27)$. During human fetal development, lymphocytes that can be categorized as $\mathrm{T}$ and $\mathrm{B}$ appear by the end of the first trimester of pregnancy $(3,6,30)$. T cells reach adult levels by 30-32 wk of gestation (24). Similar information on the ontogeny of $\mathrm{C}^{\prime}$ receptor+ and FcIgG receptor+ lymphocytes is not available in humans. Whereas $\mathrm{C}^{\prime}$ receptor+ lymphocytes are at adult levels in the fetal lambs, FcIgG receptor+ lymphocytes are seen at significantly lower numbers. FcIgG receptors are demonstrable on $\mathrm{T}$ and $\mathrm{B}$ lymphocytes and on lymphocytes belonging to the $\mathrm{NK} / \mathrm{K}$ cell system. The decrease in the number of FcIgG receptor+ lymphocytes may be due to a decrease in any one of these lymphocyte subpopulations. It may also be due to a maturational delay in receptor expression on the cell surface, and, as such, there may be a decrease in FcIgG receptor expression on other cell types, like monocytes and granulocytes. Studies are under way to explore these possibilities. The decrease in the number of these cells in the fetus may be related to the marked impairment in the generation of all-specific cytotoxic cells during MLC responses in the fetal lamb (14). It may also be related to the deficiency in lymphokine synthesis that we demonstrated.

In the fetus, where maternal antibodies against the paternal allotypes may be present, a decrease in $\mathrm{Fc}$ receptor-mediated function of antibody-dependent cellular cytotoxicity may perhaps be necessary to prevent immunologic reactivity against paternal allotypes and subsequent cell damage. But in the neo- 
nate, where maternal antibodies against environmental pathogens are available, either transplacentally or via the colostrum, $\mathrm{Fc}$ receptor-mediated function of antibody-dependent cellular cytotoxity is of considerable importance in the immediate control of pathogens. A developmental delay in the Fc receptor-mediated function would considerably impair host defense.

Fetal MNL proliferated in response to phytomitogens and this response was comparable to adult responses. This previously undocumented finding was expected in view of results in the human fetus where MNL proliferative responses are first demonstrable by the end of first trimester of pregnancy and gradually reach adult levels by $30-32$ wk of gestation $(3,25,26)$.

The ovine species, like other mammals, demonstrate cellular antigens determined by the MHC, which are responsible for proliferative responses in MLC. Fetal lamb MNL proliferated in response to alloantigens, presented as stimulator cells from unrelated adults. This confirms the observations of Granberg and Hirvonen (14). Comparable MLC responses are seen in the human fetus during this period in gestation (24). The effects of one and two haplotype identity on MLC reactions in the sheep are demonstrated by the differential responses to twin, maternal, and allogeneic adult cells. The response to the maternal stimulator cells, which were presumably one haplotype identical, was roughly half of the response seen with unrelated adult stimulator cells. The non-responsiveness to twin cells may be due either to identity at the MHC locus or intrauterine exposure to twin cells through placental vascular anastamoses between the twins which have been reported in sheep (18).

Immunocompetent lymphocytes, while responding to mitogens and antigens by proliferation, also liberate soluble factors or lymphokines which exert far-reaching modulating effects on lymphocytes and other cell types. Various lymphokines, with differing physico-chemical characteristics and varying actions upon target tissues, have been described in other mammals. Our study documents the production by sheep MNL of a lymphokine that is chemotactic for PMN in response to mitogen stimulation. Lymphokine generation in other mammals was shown to be independent of proliferation and dependent upon the presence of macrophages (12). Human cord MNL have been found to be deficient in the synthesis of some but not all the lymphokines tested while maintaining normal proliferative responses $(7,11$, $15,16,20,24)$. These observations suggest a dichotomy between the proliferative phase of immune response and mediator production. Our observations of deficient lymphokine production with normal proliferative responses to phytohemagglutinin by fetal lamb MNL extends this concept to the ovine species. The clinical relevance of mediator deficiency during gestation, which is a period of intense immunologic stimulation for the mother as well as the fetus, is unclear at the present time. Lymphokine production during MLC reaction was documented in other mammals (22). Because proliferation is not required for mediator production, lymphokines could be produced either by the responding or stimulating cells under those circumstances. Our studies do not point toward the cause of deficient lymphokine production by fetal MNL. Macrophages which are required for lymphokine production demonstrate sequential maturation of function $(1,4,5,6)$. A recent study suggested that the defective immune interferon production by human cord MNL was due to a macrophage defect (28); thus, it is possible that deficient $\mathrm{N}$ LDCF synthesis by fetal MNL is due to a developmental delay in either lymphocytes or macrophage function. Additional coculture studies are required to explore these possibilities and are under way.

The newborn emerges from an antigen-laden intrauterine environment where immunologic reactivity is perhaps least required into an antigen-laden extrauterine environment requiring a completely functional immune system for survival. The biologic relevance of the sequences in the ontogeny of mammalian immune system is better appreciated when interpeted in this context.

In summary, we have shown that the fetal lamb possesses normal numbers of circulating $T$ and $B$ lymphocytes at and after $120 \mathrm{~d}$ of gestation. Lymphocyte proliferative responses to mitogens and alloantigens are comparable to adult sheep and to human fetus of comparable gestational age (32-40 wk). Circulating FcIgG receptor+ lymphocytes are significantly reduced in the fetal lamb. We demonstrated the production of the lymphokine N-LDCF in the adult sheep and the failure of production of this lymphokine in the fetus. The significance of decrease in FcIgG receptor+ lymphocytes and deficient lymphokine synthesis is unclear at the present time. These data point to the remarkable similarity between the ovine and human fetus in the development of cellular immunity. The fetal lamb has been shown to be an excellent animal model for a variety of maturing biologic systems, including the immune system. We hope that the new data presented in this study suggest avenues of future research in this tested animal model.

\section{REFERENCES AND NOTES}

1. Argyris, B. F.: Role of macrophages in immunological maturation. J. Expl. Med., 128: 459 (1968).

2. Asantila, T and Toivanen, P.: Specificity of allogeneic and xenogeneic cell recognition in the fetal lamb. J. Immunol,, 117: 535 (1976).

3. August, C. S., Berkel, A. I., Driscoll, S. and Merker, E. Onset of lymphocyte function in the developing human fetus. Pediatr. Res., 5: 539 (1971).

4. Blaese, R. M.: Macrophages and the development of immunocompetence. In: Bellanti, J. A. and D. H. Dayton: The Phagocytic Cell in Host Resistance. p. 309 (New York, Raven Press, 1975)

5. Blaese, R. M. and Lawrence, E. C.: Development of macrophage function and the expression of immunocompetence. In: Cooper, M. D. and D. H. Dayton: Development of Host Defenses. pp. 201-211 (New York, Raven Press, 1977).

6. Bellanti, J. A., Nerurkar, L. S. and Zeligs, B. J.: Host defenses in the fetal and neonate. Pediatrics, 64(S): 726 (1979).

7. Cantill, K., Strander, H., Saxen, L. and Meyer, B. Interferon response of human leucocytes during intrauterine and postnatal life. J. Immunol., 100 . 1304 (1968)

8. Chandra, P., Chanana, A. D., and Joel, D. D.: Distribution of T and B lymphocytes in blood and lymphoid tissues of fetal and adult sheep. Am. J. Vet. Res, 4l: 2092 (1980).

9. Cole, F. J. and Morris, B.: The growth and development of lambs thymectomized in utero. Aust. J. Exp. Biol. Med. Sci., 49: 33 (1971).

10. Cole, F. J. and Morris, B.: Antigen response of lambs thymectomized in utero. Aust. J. Exp. Biol. Med. Sci., 49: 54 (1971).

11. Eife, R. F. Eife, G., August, C. S., Kuhre, W. L., and Staehr-Johansen, K. Lymphotoxin production and blast cell transformation by newborn lymphocytes: dissociated lymphocyte function in newborn infants. Cell Immunol., 14: 435 (1974).

12. Epstein, L. B., Kreth, H. W. Herzenberg, L. A. Fluorescence-activated cel sorting of human T and B lymphocytes. Cell. Immunol. 12: 407 (1974).

13. Fahey, K. J.: Humoral and cell-mediated immune response in foetal sheep following vaccination with BCG. Aust. J. Exp. Biol. Med. Sci., 55: 419 (1977)

14. Granberg, E. and Hirvonen, T.: Cell-mediated lympholysis by fetal and neonatal lymphocytes in sheep and man. Cell Immunol., 51: 13 (1980).

15. Hahn, T., Levin, S., and Handzel, Z. T.: Leukocyte migration inhibition factor (LIF) production by lymphocytes of normal children, newborns and children with immunodeficiency. Clin. Exp. Immunol., 24: 448 (1976).

16. Keller, M. A., Kidd, R. M., Leake, R. M., Everett, S. L.: LDCF production by neonatal lymphocytes. Pediatr. Res., 17: 799 (1983)

17. Leino, A. Ontogeny of PHA and Con A responses in the fetal lamb. Clin Immunol. Immunopathol., 11: 6 (1978).

18. Morrow, D. A.: David A. Morrow: Current Therapy in Theriogenology. p. 131 (W. B. Saunders, Philadelphia, 1980).

19. Raghunathan, R., Wuest, C., Faust, J., Huang, S., and Miller, M.E. Isolation of ovine lymphocytes, granulocytes and monocytes using counterflow centrifugation elutriation. Am. J. Vet. Res., 43: 1467 (1982).

20. Ray, C. G.: The ontogeny of interferon production in human leucocytes. J. Pediatr. 76: 94 (1970).

21. Silverstein A. M: Ontogeny of the immune response. Science, 144: 1423 (1964).

22. Synderman, R., Meadows, L., and Amos, D. B.: Microassay for human chemotactic lymphokine. Cell Immunol., 30: 225 (1977).

23. Solomon, J. B.: The unification of foetal and post-natal immunology in mammals and birds by age-equivalence. In: Foetal and neonatal immunology. (Elsevier Publishing Co. Inc., New York, 1971).

24. Stiehm, E. R., Winter, H. S., and Bryson, Y. J.: Cellular (T-cell) immunity in the human newborn. Pediatrics, $64(S): 814$ (1979).

25. Stites, D. P., Carr, M. C., and Fudenberg, H. H.: Ontogeny of cellular immunity in the human fetus: Development of responses to phytohemagglutinin and allogeneic cells. Immunology, 11: 257 (1974).

26. Stites, D. P. and Pavis, C. S.: Ontogeny of human $T$ cells. Pediatrics $64(S)$ : 795 (1978).

27. Symons, D. B. A. and Binns, R. M.: Ig bearing lymphocytes: Their demonstra- 
tion in adult sheep and ontogeny in the sheep fetus. Intern. Arch. Allergy Appl. Immunol., 49: 658 (1975)

28. Taylor, S. and Bryson, Y. V.: Impaired production of immune (PHA-induced) interferon in newborns is due to a functionally immature macrophage. Pediatr. Res. (abstract), 15: 604 (1981).

29. Wu, S., Bach, F. H., and Auerbach, R.: Cell-mediated immunity: differential maturation of mixed leucocyte reaction and cell mediated lympholysis. $\mathbf{J}$. Exp. Med., 142: 1301 (1975).

30. Wybran, L., Carr, M. C., and Fudenberg, H. H.: Effect of serum on human rosette forming cells in fetuses and adult blood. Clin. Immunol. Immunopathoi., $1: 408$, (1973).

31. Requests for reprints should be addressed to: Dr. Rukmani Raghunathan, Dept. of Pediatrics, UCLA School of Medicine, Harbor-UCLA 100 W. Carson St., Torrance, CA 90509.

32. This research was supported by NICHD Progam Project 1-PO1 HD10975$04 \mathrm{~A} 1$.

33. Received for publication November $16,1982$.

34. Accepted for publication July 14,1982 .

\title{
Circadian Rhythms of Blood Minerals during Adolescence $^{(41)}$
}

\author{
MORRI E. MARKOWITZ, ${ }^{(40)}$ JOHN F. ROSEN, SWAMY LAXMINARAYAN, AND \\ MARK MIZRUCHI \\ Department of Pediatrics, Clinical Research Center, Computer Center, Albert Einstein College of Medicine, \\ Montefiore Medical Center, Bronx, New York and Computer Center, New Jersey College of Medicine, \\ Newark, New Jersey, USA
}

\begin{abstract}
Summary
Sequential blood sampling every 30 min was performed in six adolescent males. Samples were analyzed for serum phosphate $\left(\left(P_{i}\right)\right.$, total calcium $\left(\mathbf{C a}_{T}\right)$, and blood ionized calcium $\left(\mathbf{C a}^{++}\right)$ concentrations. A circadian (24-h) pattern was observed for each mineral: 1) $\mathrm{Ca}^{++}$concentrations followed a $\mathrm{U}$-shaped curve with a peak at $11 \mathrm{AM}$ and a trough at 3:30 PM; 2) Ca concentrations followed a W-shaped curve with maxima at 11 and $1 \mathrm{AM}$ and troughs at $5 \mathrm{AM}$ and $6 \mathrm{PM}$; and 3) $\mathrm{P}_{\mathrm{i}}$ concentrations followed an M-shaped curve with peaks at $4 \mathrm{PM}$ and 3:30 AM. The overall mineral patterns were similar in shape to those previously decribed in adult males. In contrast, however, the amplitude of the $P_{i}$ fluctuations were considerably greater in the adolescents compared with that in adults $(3.0 \mathrm{mg} / \mathrm{dl}$ versus $1.2 \mathrm{mg} / \mathrm{dl})$. The $\mathrm{Ca}^{++}$pattern diverged from the $\mathrm{Ca}_{\mathrm{T}}$ pattern during the nocturnal phase to an extent that neither pattern could be predicted from the other. Ultradian rhythms were found in some of the time series mineral data sets; however, no single frequency encompassed all subjects for each circulating mineral.
\end{abstract}

Several hormones and minerals undergo daily rhythmic variations in their circulating concentrations $(4,6,22,32)$. Disturbances in these rhythms are manifestations of specific disease states $(5,28)$. Determination of normal rhythms aids in understanding physiologic processes and provides a rational basis for interpretation of laboratory data and possible therapeutic intervention.

In a recent investigation, we found that the 24-h pattern of blood ionized calcium $\left(\mathrm{Ca}^{++}\right)$concentrations in human males can be described by a U-shaped curve with a peak at 9:30-10:00 AM and a trough at 6:00-7:00 PM (18). The circadian (24-h) rhythm of serum phosphate $\left(\mathrm{P}_{\mathrm{i}}\right)$ concentrations was described by a curve with major and minor peaks at $2 \mathrm{AM}$ and $4 \mathrm{PM}$, respectively (18). The $P_{i}$ pattern was not predictable from changes in $\mathrm{Ca}^{++}$. Serum total calcium $\left(\mathrm{Ca}_{\Upsilon}\right)$ concentrations fluctuated inversely with $\mathrm{P}_{\mathrm{i}}$ and also could not be predicted consistenly from changes in $\mathrm{Ca}^{++}$concentrations (18). Other studies have found nocturnal elevation in serum $\mathrm{P}_{\mathrm{i}}$ concentration, and either a nocturnal fall or no diurnal variation in $\mathrm{Ca}_{\mathrm{T}}$ concentrations ( 7 , $15,17,30,33)$. To date, one other study of $24-\mathrm{h} \mathrm{Ca}^{++}$concentrations was performed in postmenopausal women (25). These authors reported a similar but phase-shifted $\mathrm{Ca}^{++}$pattern.

Several hormones progress through a pubertal-stage-associated maturation in their 24-h patterns (32). To determine whether ontogeny occurs during the development of blood mineral rhythms, we extended our studies to a group of six healthy male teenagers. Adolescence was chosen because this period is one of increased bone re-cycling rates, thereby maximizing (perhaps) the likelihood of finding mineral patterns different from those in adults (2). The study was limited to males in order to avoid the confounding effects of sex hormone fluctuations that occur during the menstrual cycle $(27,31)$. We found mineral patterns that were similar in shape and duration to those in adults; however, the amplitude in the daily phosphate fluctuations was considerably greater in teenagers, compared with that in adults.

\section{MATERIALS AND METHODS}

Subjects. Six healthy adolescent males, aged 13-17 yr and Tanner 4 and 5, participated in this study after informed consent was obtained from both parents and subjects. None had any history of recent fractures, immobilization, endocrine, bone, renal or liver disease, increased mineral or vitamin D intake, or drug use. All had nocturnal sleeping habits. Pre-study physical examinations were normal.

Protocol. Pairs of teenagers were admitted to the Clinical Research Center on the night before the study to adapt to the facilities. These consisted of a two-room suite with toilet. A technician remained in the outer chamber throughout the study and was responsible for blood sampling, event logging, and EEG recordings to confirm sleep time. The subjects had proscribed daytime activities and were not allowed to sleep. Lights out occurred at midnight. A fixed diet-consisting of approximately $400 \mathrm{mg}$ calcium, $900 \mathrm{mg}$ phosphate, and $200 \mathrm{IU}$ of vitamin Dwas divided into three meals given at 8:30 AM, 12 noon, and 5:30 PM.

On the morning after admission, an indwelling venous catheter was placed in an anticubital vein. To maintain catheter patency 